\title{
Leeches as the intermediate host for strigeid trematodes: genetic diversity and taxonomy of the genera Australapatemon Sudarikov, 1959 and Cotylurus Szidat, 1928
}

\author{
Ewa Pyrka ${ }^{1}$, Gerard Kanarek ${ }^{2^{*}} \mathbb{0}$, Grzegorz Zaleśny $^{3}$ and Joanna Hildebrand ${ }^{1}$
}

\begin{abstract}
Background: Leeches (Hirudinida) play a significant role as intermediate hosts in the circulation of trematodes in the aquatic environment. However, species richness and the molecular diversity and phylogeny of larval stages of strigeid trematodes (tetracotyle) occurring in this group of aquatic invertebrates remain poorly understood. Here, we report our use of recently obtained sequences of several molecular markers to analyse some aspects of the ecology, taxonomy and phylogeny of the genera Australapatemon and Cotylurus, which utilise leeches as intermediate hosts.
\end{abstract}

Methods: From April 2017 to September 2018, 153 leeches were collected from several sampling stations in small rivers with slow-flowing waters and related drainage canals located in three regions of Poland. The distinctive forms of tetracotyle metacercariae collected from leeches supplemented with adult Strigeidae specimens sampled from a wide range of water birds were analysed using the $28 \mathrm{~S}$ rDNA partial gene, the second internal transcribed spacer region (ITS2) region and the cytochrome c oxidase (COI) fragment.

Results: Among investigated leeches, metacercariae of the tetracotyle type were detected in the parenchyma and musculature of 62 specimens (prevalence 40.5\%) with a mean intensity reaching 19.9 individuals. The taxonomic generic affiliation of metacercariae derived from the leeches revealed the occurrence of two strigeid genera: Australapatemon Sudarikov, 1959 and Cotylurus Szidat, 1928. Phylogenetic reconstructions based on the partial 28S rRNA gene, ITS2 region and partial COI gene confirmed the separation of the Australapatemon and Cotylurus clades. Taking currently available molecular data and our results into consideration, recently sequenced tetracotyle of Australapatemon represents most probably Au. minor; however, unclear phylogenetic relationships between Au. burti and Au. minor reduce the reliability of this conclusion. On the other hand, on the basis of the obtained sequences, supplemented with previously published data, the metacercariae of Cotylurus detected in leeches were identified as two species: C. strigeoides Dubois, 1958 and C. syrius Dubois, 1934. This is the first record of C. syrius from the intermediate host.

Conclusions: The results of this study suggest the separation of ecological niches and life cycles between C. cornutus (Rudolphi, 1808) and C. strigeoides/C. syrius, with potential serious evolutionary consequences for a wide range of host-parasite relationships. Moreover, phylogenetic analyses corroborated the polyphyletic character of $C$. syrius, the unclear status of C. cornutus and the separate position of Cotylurus raabei Bezubik, 1958 within Cotylurus. The data

\footnotetext{
*Correspondence: kanarek@miiz.waw.pl

${ }^{2}$ Ornithological Station, Museum and Institute of Zoology, Polish Academy of Sciences, Nadwiślańska 108, 80-680 Gdańsk, Poland Full list of author information is available at the end of the article
}

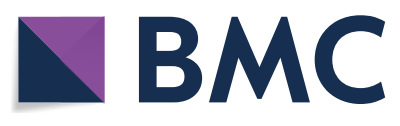

(c) The Author(s) 2021. This article is licensed under a Creative Commons Attribution 4.0 International License, which permits use, sharing, adaptation, distribution and reproduction in any medium or format, as long as you give appropriate credit to the original author(s) and the source, provide a link to the Creative Commons licence, and indicate if changes were made. The images or other third party material in this article are included in the article's Creative Commons licence, unless indicated otherwise in a credit line to the material. If material is not included in the article's Creative Commons licence and your intended use is not permitted by statutory regulation or exceeds the permitted use, you will need to obtain permission directly from the copyright holder. To view a copy of this licence, visit http://creativeco mmons.org/licenses/by/4.0/. The Creative Commons Public Domain Dedication waiver (http://creativecommons.org/publicdomain/ zero/1.0/) applies to the data made available in this article, unless otherwise stated in a credit line to the data. 
demonstrate the inconsistent taxonomic status of the sequenced tetracotyle of Australapatemon, resulting, in our opinion, from the limited availability of fully reliable, comparative sequences of related taxa in GenBank.

Keywords: Strigeidae, Leeches, Metacercariae, Australapatemon, Cotylurus

\section{Background}

Leeches (Hirudinida) are an abundant and widely distributed group of aquatic invertebrates. Aside from their significance in freshwater ecosystems as prey and predators [1], leeches are the second intermediate hosts for some trematodes from the family Strigeidae Railliet, 1919 (genera: Australapatemon Sudarikov, 1959; Cotylurus Szidat, 1928) and Cyathocotylidae Mühling, 1898 (genus Cyathocotyle Mühling, 1898) [2-5]. These genera use prosobranch or pulmonate snails as their first intermediate hosts. Cercariae that are released from snails into the aquatic environment infect and develop in leeches to the invasive stage. Metacercariae (tetracotyle type in strigeid trematodes and prohemistomulum type in cyathocotylid trematodes) that develop in leeches are transmitted to the avian definitive hosts (a wide range of Anseriformes, but also recorded in Charadriiformes and Rallidae) by ingestion [5]. Despite the recognised role of leeches in the transmission of some digenean parasites in aquatic ecosystems, there remains an insufficient understanding of host-parasite relationships within this group of annelids, and only a few studies have analysed various taxonomic (e.g. [3-6]) and ecological (e.g. [7-12]) aspects of the occurrence and diversity of digenean larval stages in leeches. Moreover, contemporary understanding of the diversity of Strigeidae trematodes has been significantly changed by the recently discovered high level of interspecific and intergeneric homogeneity of morphological features related to an unexpectedly high level of genetic diversity, revealed within the genera Australapatemon and Cotylurus [13-16]. Given these developments, several various aspects of the ecology, taxonomy and phylogeny of the genera Australapatemon and Cotylurus require urgent, detailed study. Both genera possess a long and confusing history within Strigeidae. The genus Australapatemon was erected by Sudarikov [17] on the basis of the variability of the life cycles and structure of the cercarial protonephridial system observed in several species located previously in the genus Apatemon Szidat, 1928. In view of these differences, Sudarikov [17] redefined the genus Apatemon as being characterised by cercariae with ten flame cells and metacercariae encysted in fishes and erected the new genus Australapatemon, characterised by cercariae with 14 flame cells/protonephridia and metacercariae encysted in leeches. Since then, the taxonomic status and validity of these genera have been questioned and changed several times: some authors (e.g. [18,
19]) reduced Australapatemon to the level of a subgenus within Apatemon, while Yamaguti [20] restored it to the full generic rank, as further confirmed by Niewiadomska [21]. As the morphological differences between Apatemon and Australapatemon in both metacercariae as well as adult specimens are limited or subtle, these taxa have often been incorrectly determined (for details see [6] and references therein), and thus a few attempts to use molecular markers in the identification, taxonomy and phylogeny of these genera have been made in recent years $[6,13,15,22-24]$. Importantly, a detailed molecular analysis of cercariae and adult specimens of Australapatemon sampled across North America clearly indicates the existence of several distinct lineages within this taxon and indisputably illustrates the hidden species diversity [13, 15]. In Europe, Huguenin et al. [25] identified another lineage within Australapatemon cercariae using MatrixAssisted Laser Desorption-Ionisation-Time of Flight (MALDI-TOF) mass spectrometry, but the taxonomic position and molecular diversity of larval stages of Australapatemon collected from a wide range of intermediate hosts (snails and leeches) have not been the subject of extensive studies. The genetic variability and species richness within the genus Australapatemon from various geographical regions thus remain relatively unknown.

Another genus within Strigeideae that utilises hirudineans as hosts of invasive stages is the genus Cotylurus. This genus was erected by Szidat in 1928 for strigeid parasites of birds, and is characterised by vitellaria limited to the hindbody and a well-developed genital bulb. The metacercariae of Cotylurus occur in a wide range of snails and leeches [5]. In 1958, Bezubik [26] described a new species, Strigea raabei, based on trematode specimens collected from the bursa Fabricii of the garganey Spatula querquedula and ferruginous duck Aythya nyroca from eastern Poland, characterised by the presence of vitellaria both in the hind- and forebody (typical feature of the genus Strigea) and possession of a welldeveloped genital bulb (typical of the genus Cotylurus). Regarding these combinations of morphological features as unique, Sudarikov [27] erected the new genus Cotylurostrigea and placed in it two species: Cotylurostrigea raabei and Cotylurostrigea strigeoides Dubois, 1958. However, Dubois [19] treated the genus Cotylurostrigea as a synonym of Cotylurus, while Yamaguti [20] gave Cotylurostrigea subgeneric status within the genus Strigea. Using the results of a cladistics analysis based on 
morphological and ecological features, Zazornova and Sysoev [28] recognised Cotylurostrigea as a synonym of Cotylurus, similar to Niewiadomska [21] in the most recent system of Strigeidae. In 1969, on the basis of differences in life cycles and cercariae morphology, Odening [29] erected two new subgenera within the genus Cotylurus: (i) Ichthyocotylurus, characterised by cercariae with two pairs of penetration glands located behind the ventral sucker, metacercariae in fish intermediate hosts and fish-eating birds as final hosts; (ii) Cotylurus, including species with cercariae characterised by two pairs of penetration glands located in front of the ventral sucker, metacercariae encysted in gastropods and leeches and anseriform and charadriform birds as final hosts. Niewiadomska [30] regarded these taxa as valid and elevated both subgenera to the full generic rank, as confirmed in the most recent review [21]. However, representatives of Cotylurus show huge morphological variability, which led some authors to divide it into numerous subspecies with disputable validity [19], whereas others considered it as a polymorphic species with a wide host range and cosmopolitan distribution [31]. This led to basic problems with precise and adequate delimiting of particular species, which clearly indicates the need to use molecular techniques in studies on the taxonomy and phylogeny of Cotylurus. In recent years, Heneberg et al. [14] combined a morphological and molecular analysis of central European Strigeidae from avian definitive hosts to investigate the taxonomic position of several Cotylurus species and surprisingly revealed a high level of molecular diversity within morphologically well-established species. In Canada, Locke et al. [32] and Gordy and Hanington [15] also revealed the occurrence of several new species within this genus. These results clearly indicate the need for further, detailed morphological, molecular and phylogenetic studies.

Most of the recent molecular data on the taxonomy and structure of the genera Australapatemon and Cotylurus are based on free-living larval stages (cercariae), without a simultaneous analysis of the invasive stages in second intermediate hosts or a comparative molecular and morphological analysis of adults. Moreover, the majority of contemporary studies were based on simple molecular markers enabling a fully reliable comparison of the results with other data $[15,32]$. In this article, we describe the identity and molecular diversity of tetracotyle metacercariae detected in four taxa of freshwater leeches (Erpobdella octoculata, Glossiphonia complanata, Haemopis sanguisuga and Theromyzon tessulatum), collected from three distinct localities in southern and northern Poland and based on several molecular markers (28S nuclear large ribosomal subunit gene, second internal transcribed spacer region [ITS2] ribosomal DNA
[rDNA], mitochondrial [mt] cytochrome $c$ oxidase subunit $1[\mathrm{COI}])$. Our results were supplemented by data from the yet to be sequenced Cotylurus species, collected from avian hosts from northern Poland. On this basis, we present and discuss new data on the diversity and structure of the genera Cotylurus and Australapatemon. This study is the first comprehensive attempt to fully understand the identity and diversity of strigeid metacerariae from leech intermediate hosts in central Europe.

\section{Methods}

\section{Host sampling protocols and necropsy procedures}

From April 2017 to September 2018, 153 leeches were collected from several sampling stations in small rivers with slow-flowing water and related drainage canals located in three regions of Poland: Gdańsk Pomerania, Lower Silesia and Subcarpathia Province (Table 1; Fig. 1). Leeches were collected manually, using entomological nets and home-made aluminium traps with beef liver or chicken hearts as bait. Additionally, some specimens were sampled by hand from littoral stones and bottom detritus. The leeches were transferred to a plastic box with water and adequate ventilation, transported to the laboratory and stored in the fridge. Before necropsy, leeches were identified to the species level based on morphological characteristics provided by Bielecki et al. [33]. Specimens of four species, namely Erpobdella octoculata (L., 1758), Glossiphonia complanata (L., 1758), Haemopis sanguisuga (L., 1758) and Theromyzon tessulatum Müller, 1774, were identified and examined for the presence of metacercariae (Table 1). In the case of infected leaches, taxonomic identification based on morphological features was confirmed by molecular results using the partial internal transcribed spacer (ITS) rRNA as a marker, and representative sequences were deposited in GenBank under no. MW256797 and MW256798. Leeches were initially anesthetised in $8 \%$ ethanol, then, after the cessation of movement, transferred to $70 \%$ ethanol for euthanasia [34], following which they were immediately opened longitudinally and the intestines separated from the skin and transferred to Petri dishes containing physiological sodium chloride solution where they were examined under a stereomicroscope. The distinctive forms of an unnamed tetracotyle metacercariae (both in preencystment stage and enclosed in an egg-shaped cyst) were extracted alive from the body cavity and mesenteries using preparation needles, washed in physiological sodium chloride solution, counted and fixed in hot $70 \%$ ethanol and finally preserved in the same medium for further processing. Material for further molecular analysis was randomly selected from the tetracotyle, according to the observed intensity of invasion: every 10 th or 50 th 
metacercariae (in the case of very low infection all metacercariae were sampled) from each infected host.

Several adult strigeid specimens collected from a wide range of water birds (mallard Anas platyrhynchos, gadwall Anas strepera, common pochard Aythya ferina, mute swan Cygnus olor, Eurasian coot Fulica atra) were used as reference material (Table 2). After isolation from the gastrointestinal tracts of the definitive avian hosts, the digeneas were rinsed in physiological salt solution, initially identified alive under the microscope and then fixed in hot $70 \%$ ethanol for further morphological and molecular analyses. The selected digeneans were then stained with alcohol borax carmine, dehydrated in ethanol series, cleared in clove oil and mounted in Canada balsam. Voucher specimens of adult flukes are deposited in the Polish Collection of Parasitic Helminths, Museum of Natural History, Wrocław University, Poland with collection numbers 204290 (Apatemon fuligulae Yamaguti, 1933), 204291-204292 [Cotylurus cornutus (Rudolphi, 1808)], 204293-204297 (C. hebraicus Dubois, 1934), 204298204302 [C. raabei (Bezubik, 1956)], 204303-204307 (C. strigeoides Dubois, 1958) and 204308-204315 (C. syrius Dubois, 1934).

The ecological terms used in this study are those defined by Bush et al. [35].

\section{Molecular analysis}

DNA was extracted from single, alcohol-fixed metacercariae and adult worms using a commercial kit (DNeasy Blood and Tissue kit; Qiagen, Hilden, Germany), according to the manufacturer's protocol. PCR amplification of 28S) and the ITS as well as of the mitochondrial gene encoding COI was carried using the KAPA2G Robust HotStart ReadyMix (Sigma-Aldrich, St. Louis, MO. USA) and primers selected based on the literature. A list of primers and the cycling conditions of the PCR reaction are presented in Additional file 1: Table S1.

The PCR results were visualised following electrophoresis in a $1 \%$ agarose gel. The electrophoresis products were purified using the Exo-BAP kit (EURx) or QIAquick Gel Extraction kit (Qiagen) when non-specific products were present. Purified products were sequenced directly in both directions using the PCR primers. Contiguous sequences were assembled using Geneious software (Geneious 9.1.8; https://www.geneious.com). The representative sequences were submitted to GenBank under accession numbers presented in Table 2. The alignments included newly obtained sequences and closely related representatives of Strigeidae currently available in GenBank (Additional file 1: Table S2) and were prepared using ClustalW multiple alignment implemented in MegaX [36]. Sequences of the 28S rDNA partial gene,

Table 1 Parasitological factors of leech infection

\begin{tabular}{|c|c|c|c|c|c|}
\hline Localisation & Leech species & $\begin{array}{l}\text { No. of } \\
\text { necropsied/ } \\
\text { infected leeches }\end{array}$ & $\begin{array}{l}\text { Tetracotyle } \\
\text { prevalence } \\
(\%)\end{array}$ & $\begin{array}{l}\text { Tetracotyle infection } \\
\text { intensity (min-max; } \\
\text { mean) }\end{array}$ & $\begin{array}{l}\text { Recorded Strigeidae genus (no. of } \\
\text { infected leeches/no. of leeches with } \\
\text { mixed invasions) }\end{array}$ \\
\hline \multirow[t]{2}{*}{ Gdańsk Pomerania } & \multirow[t]{2}{*}{ Haemopis sanguisuga } & \multirow[t]{2}{*}{$66 / 51$} & \multirow[t]{2}{*}{77.3} & \multirow[t]{2}{*}{$1-235 ; 23.1$} & Australapatemon sp. $(51 / 5)^{\mathrm{a}}$ \\
\hline & & & & & Cotylurus sp. $(5 / 5)^{a}$ \\
\hline \multirow[t]{6}{*}{ Lower Silesia } & \multirow[t]{2}{*}{ Erpobdella octoculata } & \multirow[t]{2}{*}{$13 / 3$} & \multirow[t]{2}{*}{23.1} & \multirow[t]{2}{*}{$1-3 ; 2.0$} & Australapatemon sp. (2) \\
\hline & & & & & Cotylurus sp. (1) \\
\hline & \multirow[t]{2}{*}{ Haemopis sanguisuga } & \multirow[t]{2}{*}{$37 / 8$} & \multirow[t]{2}{*}{21.6} & \multirow[t]{2}{*}{$1-15 ; 7.0$} & Australapatemon sp. $(8 / 2)^{\mathrm{a}}$ \\
\hline & & & & & Cotylurus sp. $(2 / 2)^{\mathrm{a}}$ \\
\hline & \multirow[t]{2}{*}{ Total } & \multirow[t]{2}{*}{$50 / 11$} & \multirow[t]{2}{*}{22.0} & \multirow[t]{2}{*}{$1-15 ; 5.6$} & Australapatemon sp. $(10 / 2)^{a}$ \\
\hline & & & & & Cotylurus sp. $(3 / 2)^{\mathrm{a}}$ \\
\hline \multirow[t]{4}{*}{ Subcarpathia province } & Glossiphonia complanata & $8 / 0$ & \multirow[t]{3}{*}{-} & \multirow[t]{3}{*}{-} & \multirow[t]{3}{*}{-} \\
\hline & Haemopis sanguisuga & $13 / 0$ & & & \\
\hline & Theromyzon tessulatum & $16 / 0$ & & & \\
\hline & Total & $47 / 0$ & - & - & - \\
\hline \multirow[t]{8}{*}{ TOTAL } & \multirow[t]{2}{*}{ Erpobdella octoculata } & \multirow[t]{2}{*}{$13 / 3$} & \multirow[t]{2}{*}{23.1} & \multirow[t]{2}{*}{$1-3 ; 2.0$} & Australapatemon sp. (2) \\
\hline & & & & & Cotylurus sp. (1) \\
\hline & Glossiphonia complanata & $8 / 0$ & - & - & - \\
\hline & \multirow[t]{2}{*}{ Haemopis sanguisuga } & \multirow[t]{2}{*}{$116 / 59$} & \multirow[t]{2}{*}{50.9} & \multirow[t]{2}{*}{$1-235 ; 20.8$} & Australapatemon sp. $(59 / 8)^{a}$ \\
\hline & & & & & Cotylurus sp. $(8 / 7)^{\mathrm{a}}$ \\
\hline & Theromyzon tessulatum & $16 / 0$ & - & - & - \\
\hline & \multirow[t]{2}{*}{ TOTAL } & \multirow[t]{2}{*}{$153 / 62$} & \multirow[t]{2}{*}{40.5} & \multirow[t]{2}{*}{$1-235 ; 19.9$} & Australapatemon sp. $(61 / 8)^{\mathrm{a}}$ \\
\hline & & & & & Cotylurus sp. $(9 / 8)^{\mathrm{a}}$ \\
\hline
\end{tabular}

\footnotetext{
a Mixed invasions of Australapatemon sp. and Cotylurus sp. were detected
} 


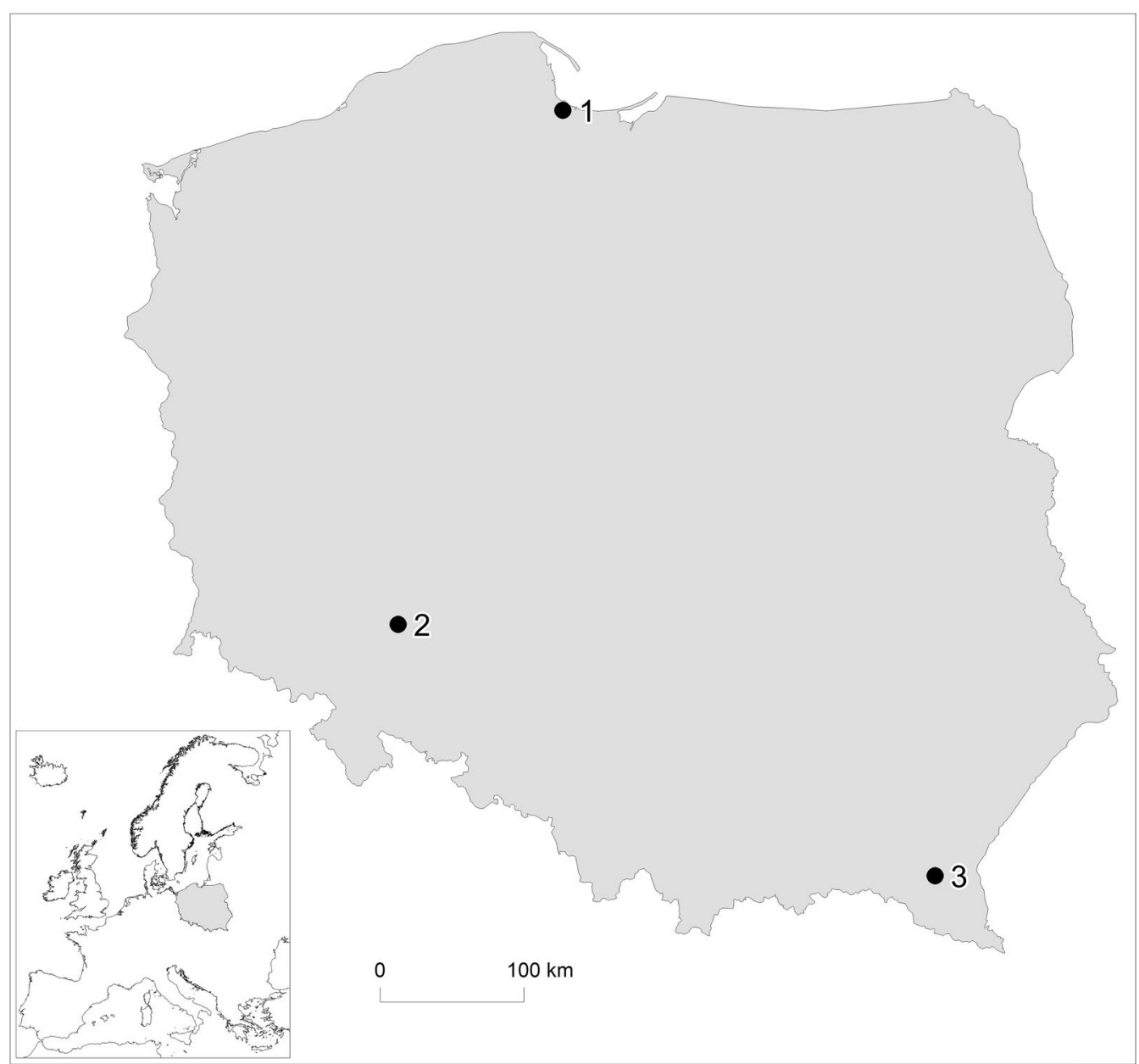

Fig. 1 Map of the sampling stations: 1 Gdańsk Pomerania, 2 Lower Silesia, 3 Subcarpathia Province

ITS2 region and the COI fragment were aligned in three independent datasets. Phylogenetic analyses were conducted using Bayesian inference criteria as implemented in MrBayes ver. 3.2.7 software [37] and were run on the three datasets individually. The general time-reversible model with estimates of invariant sites and gamma distributed among-site variation $(\mathrm{GTR}+\mathrm{I}+\mathrm{G})$ was identified as the best-fitting nucleotide substitution model for $28 \mathrm{~S}$ and COI, and the Hasegawa-Kishino-Yano substitution model with gamma distributed among-site variation $(\mathrm{HKY}+\mathrm{G})$ for ITS2, using jModelTest 2 software [38]. The consensus trees were visualised in FigTree ver. 1.4.4 software [39] and annotated in CorelDraw ${ }^{\circledR}$ (Corel Corp., Ottawa, ON, Canada).

We also used GMYC analysis (the Generalised Mixed Yule Coalescent Model) as a tool for species delimitation $[40,41]$. This method works for a single locus tree; we used the COI sequence to construct an ultrametric tree with BEAST v. 2.4.4 [42]. Prior to analysis the alignment was collapsed to unique haplotypes and the outgroupvremoved. Thus, the GMYC analysis contained 34 haplotypes, the nucleotide substitution model was set to HKY + G and we used the coalescent model with constant population size (which is the most appropriate for modeling the relationships among individuals from the same species) with strict clock. GMYC analysis was done in R software ( $\mathrm{R}$ v. 4.0.2; R Foundation for Statistical Computing, Vienna, Austria) with the following packages: 'ape,' 'paran', 'rncl' and 'splits'.

\section{Results}

Parameters of infection

Of the the 153 leeches investigated, metacercariae of the tetracotyle type (both encysted and non-encysted) were detected in the parenchyma and musculature of 62 specimens (overall prevalence 40.5\%) from two localities: Gdańsk Pomerania (51 infected among 66 H. sanguisuga investigated) and Lower Silesia (3 infected among 13 
Table 2 List of sequences of strigeids obtained in this study

\begin{tabular}{|c|c|c|c|c|c|}
\hline \multirow[t]{2}{*}{ Digenean taxa } & \multirow{2}{*}{$\begin{array}{l}\text { Host species and geographic } \\
\text { region of Poland }\end{array}$} & \multirow{2}{*}{$\begin{array}{l}\text { Life cycle } \\
\text { stage }^{\mathrm{a}}\end{array}$} & \multicolumn{3}{|c|}{ Own number/GenBank number } \\
\hline & & & $\mathrm{COI}$ & 285 & ITS \\
\hline Apatemon fuligulae & $\begin{array}{l}\text { Aythya ferina } \\
\text { Gdańsk Pomerania }\end{array}$ & A & S3/ MW204830 & S3/MW244636 & S3/MW244656 \\
\hline Australapatemon sp. & $\begin{array}{l}\text { Anas strepera } \\
\text { Gdańsk Pomerania }\end{array}$ & A & 1809/MW204820 & 1809/MW244635 & 1809/MW244655 \\
\hline Australapatemon sp. & $\begin{array}{l}\text { Haemopis sanguisuga } \\
\text { Gdańsk Pomerania }\end{array}$ & M & $\begin{array}{l}\text { PG1/MW204826 } \\
\text { PG2/MW204827 } \\
\text { PG4/MW204828 } \\
\text { PG5/MW204829 }\end{array}$ & $\begin{array}{l}\text { PG1/MW244633 } \\
\text { PG2/MW244634 } \\
- \\
-\end{array}$ & $\begin{array}{l}\text { PG1/MW244650 } \\
\text { PG2/MW244651 } \\
- \\
-\end{array}$ \\
\hline Australapatemon sp. & $\begin{array}{l}\text { Haemopis sanguisuga } \\
\text { Lower Silesia }\end{array}$ & M & $\begin{array}{l}\text { PS2/MW204821 } \\
\text { PS3/MW204822 } \\
\text { PS4/MW204823 } \\
\text { PS5/MW204824 } \\
\text { PS7/MW204825 }\end{array}$ & $\begin{array}{l}\text { PS2/MW244630 } \\
\text { PS3/ MW244631 } \\
- \\
- \\
-\end{array}$ & $\begin{array}{l}- \\
\text { PS3/ MW244654 } \\
- \\
\text { PS5/ MW244653 } \\
-\end{array}$ \\
\hline Australapatemon sp. & $\begin{array}{l}\text { Erpobdella octoculata } \\
\text { Lower Silesia }\end{array}$ & M & - & PS11/MW244632 & PS11/MW244652 \\
\hline Cotylurus cornutus & $\begin{array}{l}\text { Anas platyrhynchos } \\
\text { Gdańsk Pomerania }\end{array}$ & A & S10/MW204806 & S10/MW244637 & S10/MW244657 \\
\hline Cotylurus hebraicus & $\begin{array}{l}\text { Fulica atra } \\
\text { Gdańsk Pomerania }\end{array}$ & A & $\begin{array}{l}\text { 1443/MW204805 } \\
-\end{array}$ & $\begin{array}{l}\text { 1443/MW244638 } \\
\text { 1492/MW244639 }\end{array}$ & $\begin{array}{l}\text { 1443/MW244667 } \\
\text { 1492/MW244668 }\end{array}$ \\
\hline Cotylurus raabei & $\begin{array}{l}\text { Anas platyrhynchos } \\
\text { Gdańsk Pomerania }\end{array}$ & A & S2/MW204804 & S2/MW244649 & S2/MW244669 \\
\hline Cotylurus strigeoides & $\begin{array}{l}\text { Anas platyrhynchos } \\
\text { Gdańsk Pomerania }\end{array}$ & $A$ & S9/MW204807 & S9/MW244640 & S9/MW244658 \\
\hline Cotylurus syrius & $\begin{array}{l}\text { Cygnus olor } \\
\text { Lower Silesia }\end{array}$ & A & LD/MW204819 & LD/MW244648 & LD/MW244666 \\
\hline Cotylurus syrius & $\begin{array}{l}\text { Cygnus olor } \\
\text { Małopolska Region }\end{array}$ & A & LK/MW204818 & LK/MW244647 & LK/MW244665 \\
\hline Cotylurus sp. & $\begin{array}{l}\text { Haemopis sanguisuga } \\
\text { Gdańsk Pomerania }\end{array}$ & M & $\begin{array}{l}\text { PG3/MW204814 } \\
\text { PG6/MW204816 } \\
\text { PG8/MW204815 } \\
\text { PG9/MW204817 }\end{array}$ & $\begin{array}{l}\text { PG3/MW244644 } \\
- \\
\text { PG8/MW244645 } \\
\text { PG9/MW244646 }\end{array}$ & $\begin{array}{l}\text { PG3/MW244661 } \\
- \\
\text { PG8/MW244660 } \\
\text { PG9/MW244664 }\end{array}$ \\
\hline Cotylurus sp. & $\begin{array}{l}\text { Haemopis sanguisuga } \\
\text { Lower Silesia }\end{array}$ & M & $\begin{array}{l}\text { PS1/MW204808 } \\
\text { PS3/MW204809 } \\
\text { PS5/MW204810 } \\
\text { PS8/MW204811 }\end{array}$ & $\begin{array}{l}\text { PS1/MW244641 } \\
- \\
\text { PS5/MW244643 } \\
-\end{array}$ & $\begin{array}{l}\text { PS1/MW244659 } \\
- \\
\text { PS5/MW244662 } \\
-\end{array}$ \\
\hline Cotylurus sp. & $\begin{array}{l}\text { Erpobdella octoculata } \\
\text { Lower Silesia }\end{array}$ & M & $\begin{array}{l}\text { PS10/MW204812 } \\
\text { PS12/MW204813 }\end{array}$ & $\begin{array}{l}\text { PS10/MW244642 } \\
-\end{array}$ & $\begin{array}{l}\text { PS10/MW244663 } \\
-\end{array}$ \\
\hline
\end{tabular}

$\mathrm{COI}$, Cyclooxygenase gene; ITS, Internal transcribed spacer region

${ }^{a} \mathrm{~A}$, Adult; $\mathrm{C}$, cercaria; $\mathrm{M}$, metacercaria

necropsied specimens of Erpobdella octoculata and 8 infected among $37 \mathrm{H}$. sanguisuga); none of the specimens of G. complanata and T. tessulatum were infected (Table 1). The highest prevalence of metacercariae was observed among leeches collected from Gdańsk Pomerania (Table 1). Leeches sampled in Subcarpatia Province were not infected. Regarding host species, the highest prevalence was observed in $H$. sanguisuga (59 infected, prevalence $50.9 \%$ ).

The highest mean intensity was detected among leeches from Gdańsk Pomerania [23.1 individuals (ind.)]; a much lower mean prevalence was recorded in Lower Silesia (5.6 ind.). Regarding host species, the highest mean intensity was noted in H. sanguisuga (20.8 ind.) (Table 1).

\section{Molecular identification of detected metacercariae and phylogenetic analyses}

The taxonomic generic affiliation of encysted and nonencysted metacercariae derived from leeches was conducted based on BLAST (Basic Local Alignment Search Tool) comparison of sequences of $28 \mathrm{~S}$ rDNA and resulted in confirmation of the occurrence of two strigeid genera: Australapatemon and Cotylurus.

Although comprehensive molecular studies of the structure of the Strigeidae are rather rare in the literature, 
a few taxonomic studies concerning the systematic position of several genera within this family have been published recently $[6,14]$. Based on the results of these studies, and given the main aim of the current study (identification and molecular diversity of strigeid metacercariae in leeches from central Europe), the structure of our datasets was determined first of all by the availability of sequences from previously published European isolates. Thus, the presented analyses are focussed mainly on the identity, molecular diversity and phylogenetic relationships within two genera from which larval stages were detected in leeches: Australapatemon and Cotylurus. As the sequences of Australapatemon and Cotylurus published previously by Heneberg et al. [14] constitute a significant part of the comparative material necessary for establishing the taxonomic position of the recently collected and analysed materials, we used the same parts of ITS region and COI gene, and also the alignments used for our phylogenetic analyses were trimmed to the length used in the cited work [14], i.e. $270 \mathrm{bp}$ for ITS2 and $295 \mathrm{bp}$ for COI. However, full-length received alignments were deposited in GenBank. The length of the $28 \mathrm{~S}$ alignment was $980 \mathrm{bp}$ and included almost all sequences of Australapatemon and Cotylurus available in GenBank, with the exception of that of C. gallinulae (length $700 \mathrm{bp}$ ). Phylogenetic reconstructions of the partial $28 \mathrm{~S}$ rRNA gene, ITS2 region and partial COI gene clearly confirmed the separation of the Australapatemon and Cotylurus clades. The obtained results do not reveal any host-parasite specificity within detected tetracotyle of Australapatemon and Cotylurus and their leech hosts (Table 1).

\section{Australapatemon}

The genetic divergence between Australapatemon specimens obtained from leeches in the present work was considered negligible based on the $28 \mathrm{~S}$ sequences and the absence of intraspecific variability within localities (Fig. 2). These sequences clustered in a well-supported clade with sequences obtained from trematodes identified as Australapatemon burti, isolates from an adult fluke from Mexico (MF398342) and cercaria from Canada (KY207625), larvae identified as Australapatemon sp. from Canada (MF124269, MF124270) and the adult form of Au. niewiadomski from New Zealand (KT334164, KT334165) (Fig. 2). The similarity of new sequences with the sequences mentioned above ranged from $99.9 \%$ (1-nucleotide difference) for $A u$. burti to $99.4 \%$ for $A u$. niewiadomski (6-nucleotide difference). The sequence of an isolate identified as Australapatemon sp. obtained from Anas strepera showed 100\% homology with previously published sequences of $A u$. burti KY207625 and MF398342 (based on 1244 and 1207 bp, respectively).
The DNA sequences of the ITS2 fragment from metacercariae sampled from leeches in the present study showed $100 \%$ identity among themselves and with sequences of $A u$. minor from Anas platyrhynchos from the Czech Republic (MF628095) and Au. burti from cercariae from Slovakia (KU950451) and Canada (KY207626), as well as with an isolate from the USA described as Australapatemon sp. (KY570947). These sequences formed one clade with trematodes identified as Au. mclaughlini (1-nucleotide difference in comparison with isolates from leeches) and $A u$. burti from Mexico (2-nucleotide difference) (Fig. 3).

Newly generated COI sequences from metacercariae collected from leeches formed a well-supported clade with Au. minor (MF6280066) within the Australapatemon branch (Fig. 4). Unfortunately, there are no available sequences of $A u$. burti that could be added to this analysis; thus, we were unable to indisputably determine the final taxonomic affiliation of isolates from leeches.

Our phylogenetic analyses carried out separately based on three genetic markers demonstrated with strong support the sister relationship among Australapatemon and some species of Apatemon: A. gracilis and Apatemon sp. "jamiesoni" (Fig. 2). However, the taxonomic position of Ap. fuligulae remains unclear: in phylogenetic reconstructions derived from the $28 \mathrm{~S}$ and ITS2 datasets this species nested between Australapatemon isolates, but according to the result of the COI analysis Ap. fuligulae from Poland and the Czech Republic clustered with Apatemon sp. "jamiesoni", although without strong support. Simultaneously, sequences of Apatemon/Australapatemon fuhrmanni, the generic affiliation of which was discussed by Heneberg et al. [14], were located inside the Australapatemon clade generated based on ITS2 and COI dataset analyses (Figs. 3, 4).

\section{Cotylurus}

The newly generated sequences of $28 \mathrm{~S}$ rDNA, the ITS2 region and COI mtDNA derived from metacercariae obtained from leeches fall in two well-supported lineages corresponding to Cotylurus strigeoides Dubois, 1958 (isolate from Anas platyrhynchos) and C. syrius Dubois, 1934 (100\% homology with isolates from Cygnus olor from Poland and the Czech Republic; accession numbers MF628093, MF628099 for ITS2 and MF628057, MF628059 for COI). The intraspecific genetic divergence between sequences in clades grouping metacercariae and the adult form of $C$. strigeoides ranged from 0 to $0.2 \%$ for the $28 \mathrm{~S}$ dataset, from 0 to $1.5 \%$ for the ITS2 dataset, and from 1 to $1.7 \%$ for the COI dataset.

The analysis of $28 \mathrm{~S}$ rDNA and COI sequences showed the distinct position of Cotylurus raabei, while other 


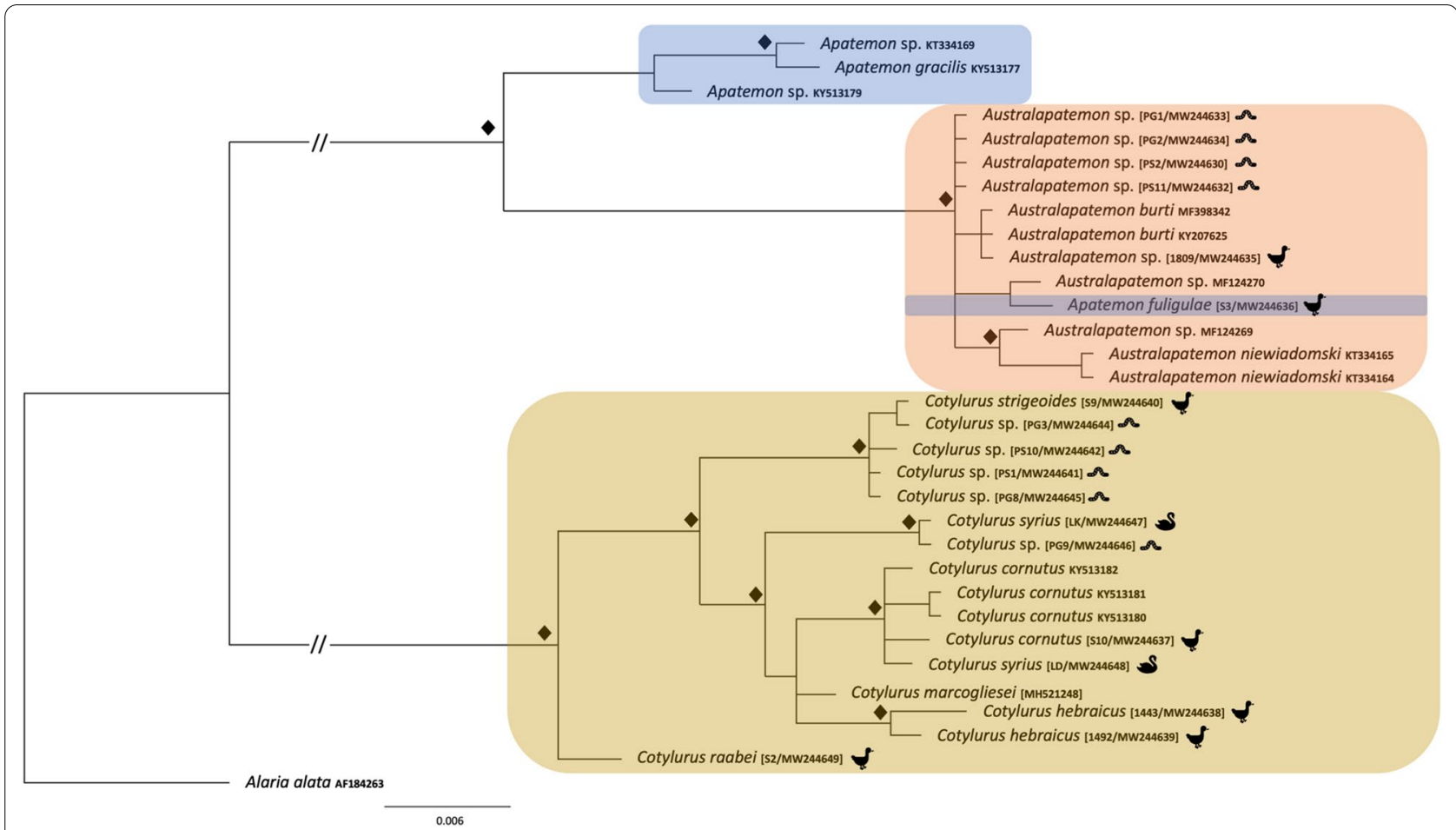

Fig. 2 The phylogenetic relationships of the Australapatemon and Cotylurus species. Analysis of the $28 \mathrm{~S}$ nuclear large ribosomal subunit gene (28S) marker based on Bayesian inference. Diamond symbol indicates a posterior probability of $>90 \%$. The pictograms placed at the names of sequences obtained in the present study reflect the host species

members of the genus Cotylurus formed the clade within which C. strigeoides appeared as a sister lineage to the group, including C. cornutus (Rudolphi, 1808), C. syrius, and recently obtained sequences of $C$. hebraicus Dubois, 1934. Moreover, all three phylogenetic analyses corroborated the polyphyletic character of $C$. syrius and also showed the unclear status of C. cornutus (Figs. 2, 3 and 4). Two recently obtained isolates of adult trematodes from Cygnus olor were located within two separate lineages of C. syrius, but two isolates from metacercariae were located within only one of them.

The sequence of $28 \mathrm{~S}$ rDNA from C. cornutus obtained in the present study (adult trematode from Anas platyrhynchos) clustered together with isolates determined as C. cornutus derived from metacercariae from Norway (KY513180-KY513182) with similarity of 99.6-99.7\%. However, due to the lack of comparative sequence material for the ITS region and COI mtDNA and the ambiguous position of our C. cornutus isolate in the trees generated based on the above datasets (Figs. 3, 4), the taxonomic position of this species remains unclear.

\section{GMYC results}

Within the 34 haplotypes GMYC analysis revealed the presence of 14 species and generally confirmed topology of clades derived by Bayesian analysis (Fig. 5). It would appear that all larval forms of strigeid flukes obtained from leeches could be matched to three species, i.e. Australapatemon minor and Cotylurus strigeoides and $C$. syrius (not shown in the tree as it had an identical haplotype to the GenBank sequence). However, in the case of the C. strigeoides and C. syrius clade, GMYC support reached $86 \%$ while for the $A u$. minor clade it was $51 \%$.

\section{Discussion}

The results of this study provide several new and important insights into the diversity of strigeid trematodes occurring in freshwater leeches in central Europe and clearly emphasise the importance of this group of aquatic invertebrates in the circulation of trematodes in the aquatic environment. The observed prevalence of tetracotyle metacercariae detected in leeches $(40.5 \%)$ was relatively high compared to that reported from other studies conducted in central and eastern Europe: during investigations of parasites of species-rich and diverse communities of leeches in the eutrophic Drużno Lake (northern Poland), Dobrowolski [3] detected larvae of strigeid and cyathocotylid trematodes among $20 \%$ of the leaches analysed, while in lakes of Kazakhastan, Zhatkanbaeva [43] and Zhatkanbaeva and Akhmetova [44] 


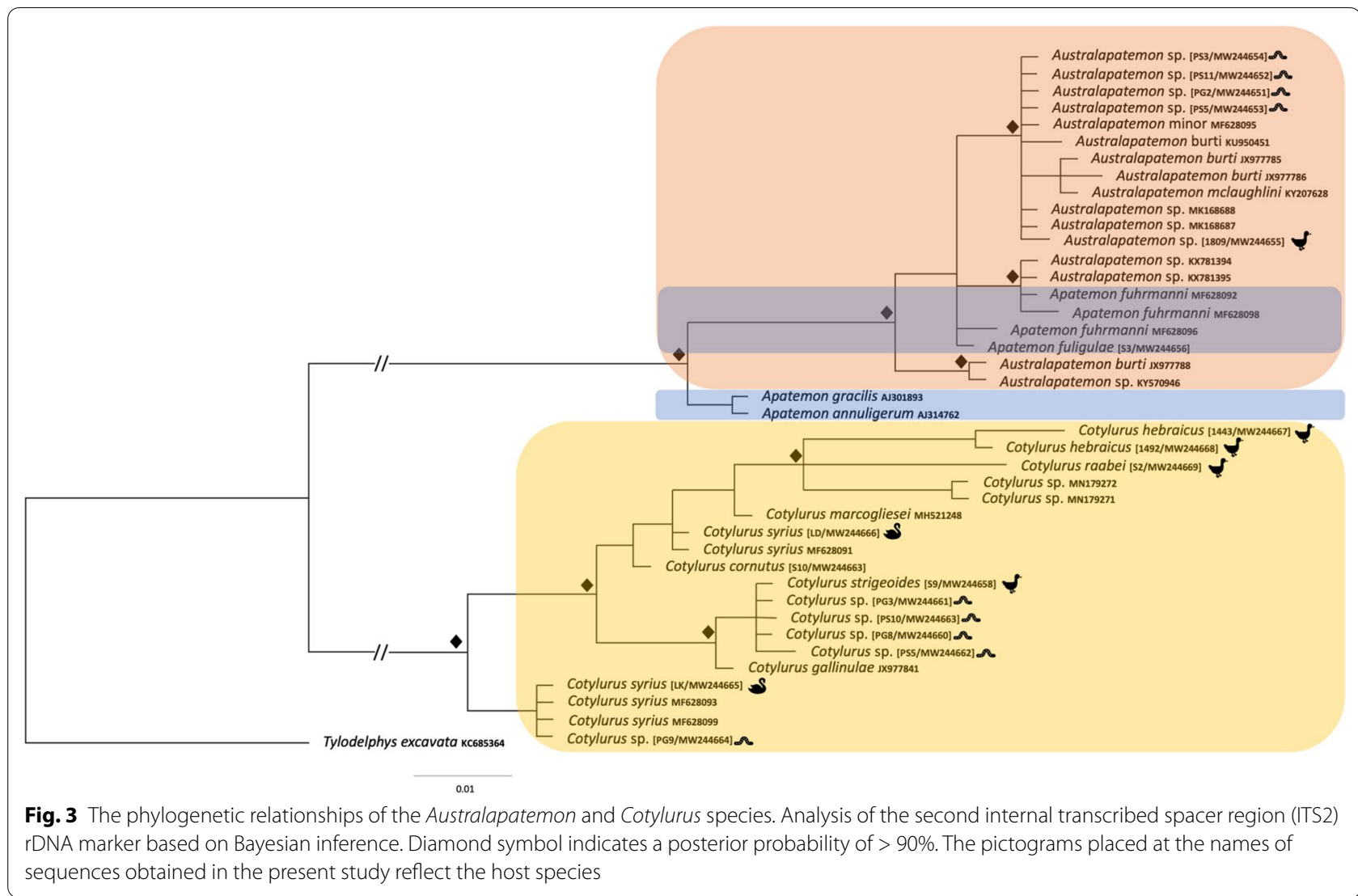

detected tetracotyle metacercariae in $19.4 \%$ of the investigated leeches. On the other hand, studies from eastern Europe have revealed the prevalence of tetracotyle metacercariae at much higher levels: in the Volga estuary Sudarikov et al. [45] found metacercariae in $60 \%$ (75 of 125) of the leeches analysed, and Rajshite [46] detected strigeid metacercariae in 53\% of leeches from the Volga and Niemen estuaries.

Tetracotyle metacercariae usually classified as Tetracotyle typica de Fillippi, 1855 have been widely recorded from snails and leeches in Europe, but their true taxonomic status has remained unknown for many years. Meanwhile, the adult form of T. typica sampled from snails has been identified as Cotylurus cornutus (Rudolphi, 1808) (for details see Sudarikov [17] and references therein). Szidat [47] reared adult trematodes from metacercariae of T. typica from the gonads of two species of leech (Erpobdella octoculata and Heamopis sanguisuga) and also identified them as Cotylurus cornutus. These results prove the possibility of the occurrence of tetracotyles of C. cornutus in two, clearly distinct groups of intermediate host, i.e. snails and leeches. The identification of T. typica from leeches as C. cornutus confirmed the results of Timon-David [48] and Dobrowolski [3]. Using material collected from leeches, Szidat [47, 49] described for the first time another type of metacercariae, Tetracotyle gracilis, and identified the adult form as Apatemon gracilis (Rudolphi, 1819). During studies on the taxonomic composition of strigeid metacercariae from leeches of the Volga estuary, Sudarikov et al. [45] confirmed the validity of $T$. gracilis as the larval form of A. gracilis but questioned the status of T. typica from leeches as $C$. cornutus. In the opinion of these authors, T. typica from leeches represents another species that is closely related to $C$. cornutus. Sudarikov et al's conclusions [45] were further confirmed by Vojtek et al. [4], who also stated that tetracotyle larvae of Cotylurus from leeches probably belong to a closely related, but different species of Cotylurus than tetracotyle larvae from snails that are commonly accepted in the contemporary literature as C. cornutus. However, these hypotheses were never confirmed, and the issue of the identity and taxonomic position of Cotylurus metacercariae occurring in leeches and snails remained unresolved for years. According to the literature, the occurrence of tetracotyles of four species of Cotylurus has been detected in leeches: C. cornutus, C. hebraicus Dubois, 1934 C. strigeoides Dubois, 1958 and C. szidati Zazornova, 1991 [5, 50-53]. Among these, tetracotyles of two species (C. cornutus, $C$. strigeoides) were also recorded from snail 


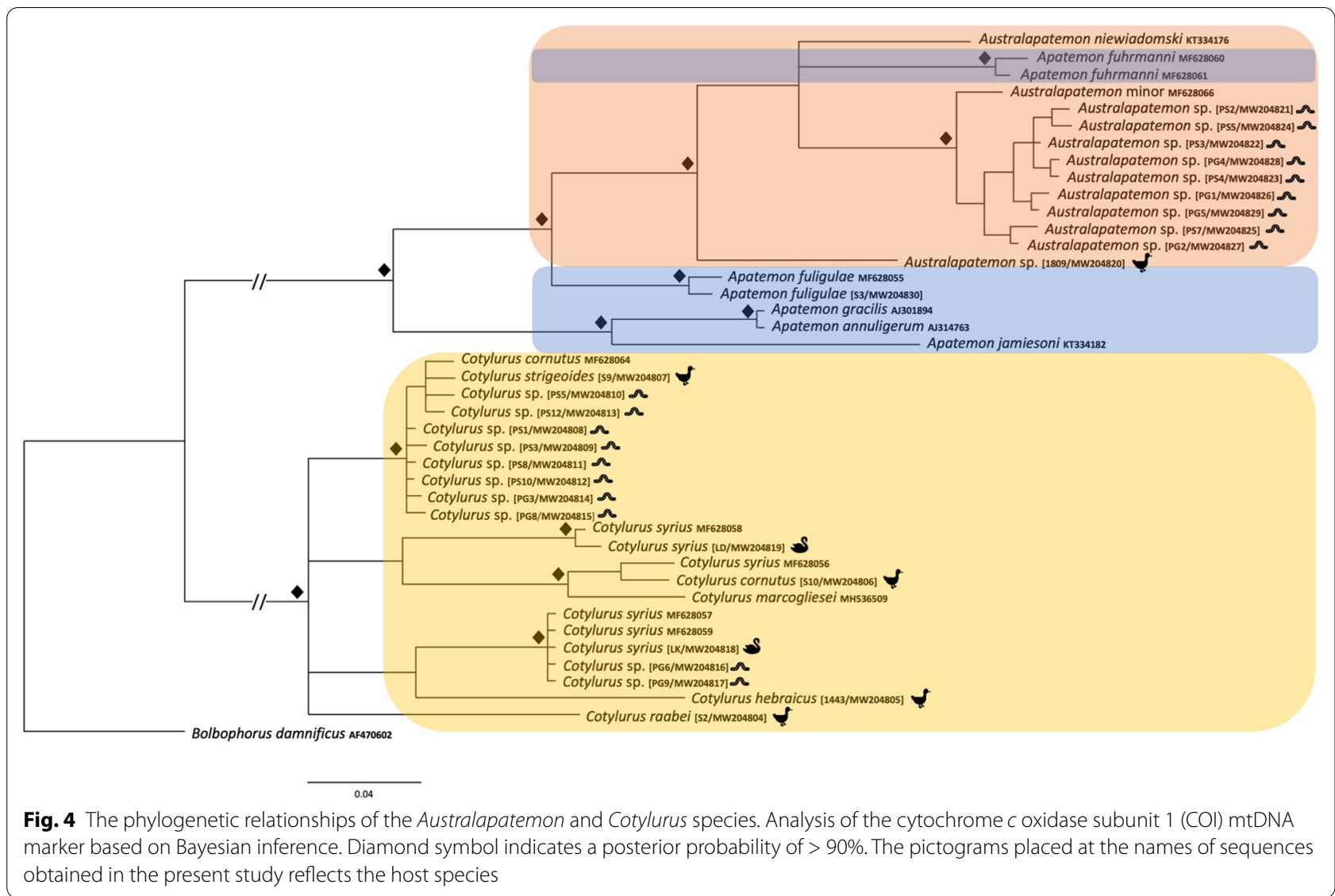

intermediate hosts $[5,50]$. However, their real taxonomic position remains doubtful because of the subtle morphological differences between the tetracotyle forms of Cotylurus [53]. Moreover, the taxonomic consequences of morphological variability observed among tetracotyles of Cotylurus have not been confirmed by molecular studies. For these reasons, recent knowledge concerning the morphology and taxonomic position of tetracotyles from snails and leeches should be considered to be highly insufficient and to require urgent verification using molecular studies based on well-determined reference materials from definitive hosts. Importantly, recent molecular studies have revealed unexpected high molecular diversity within Cotylurus [15, 32], including morphologically well-established species [14].

In the present study, metacercariae of Cotylurus detected in leeches were identified as two species, $C$. strigeoides and $C$. syrius, and this identification was confirmed by the parallel, comparative morphological and molecular analysis of adult specimens sampled from definitive avian hosts and GenBank sequences. Importantly, while leeches and snails are recognised as the second intermediate host for $C$. strigeoides [5, 53], the life cycle of $C$. syrius remains unknown. Our molecular identification of metacercariae detected in Haemopis sanguisuga from Gdańsk Pomerania as C. syrius for the first time clearly indicates the route of transmission of this strigeid to the avian definitive hosts by leeches and emphasises the importance of this invertebrate as a second intermediate host. Moreover, we consider the lack of tetracotyle forms of Cotylurus cornutus in leeches as truly surprising. In Poland, this strigeid species is one of the most important elements of the trematode fauna of anseriform birds [54]. The prevalence of C. cornutus in the population of mallard Anas platyrhynchos from Gdańsk Pomerania is about 20\% (G. Kanarek, unpublished data), which could reflect the common occurrence of its invasive stages in the aquatic environment in the study area. On the other hand, according to results obtained by Schwelm et al. [55], the distribution of larval stages (cercariae) of Cotylurus sp. within snail intermediate hosts revealed site-dependent distribution, i.e. parasites can be present in some sampling sites, but absent in others. However, the study area in Gdańsk Pomerania (near the Gulf of Gdańsk and Vistula Lagoon) is recognised as a well-known refuge of water and wetland birds with its numerous large drainage canals with slow-flowing waters, constituting a strongly homogeneous habitat 


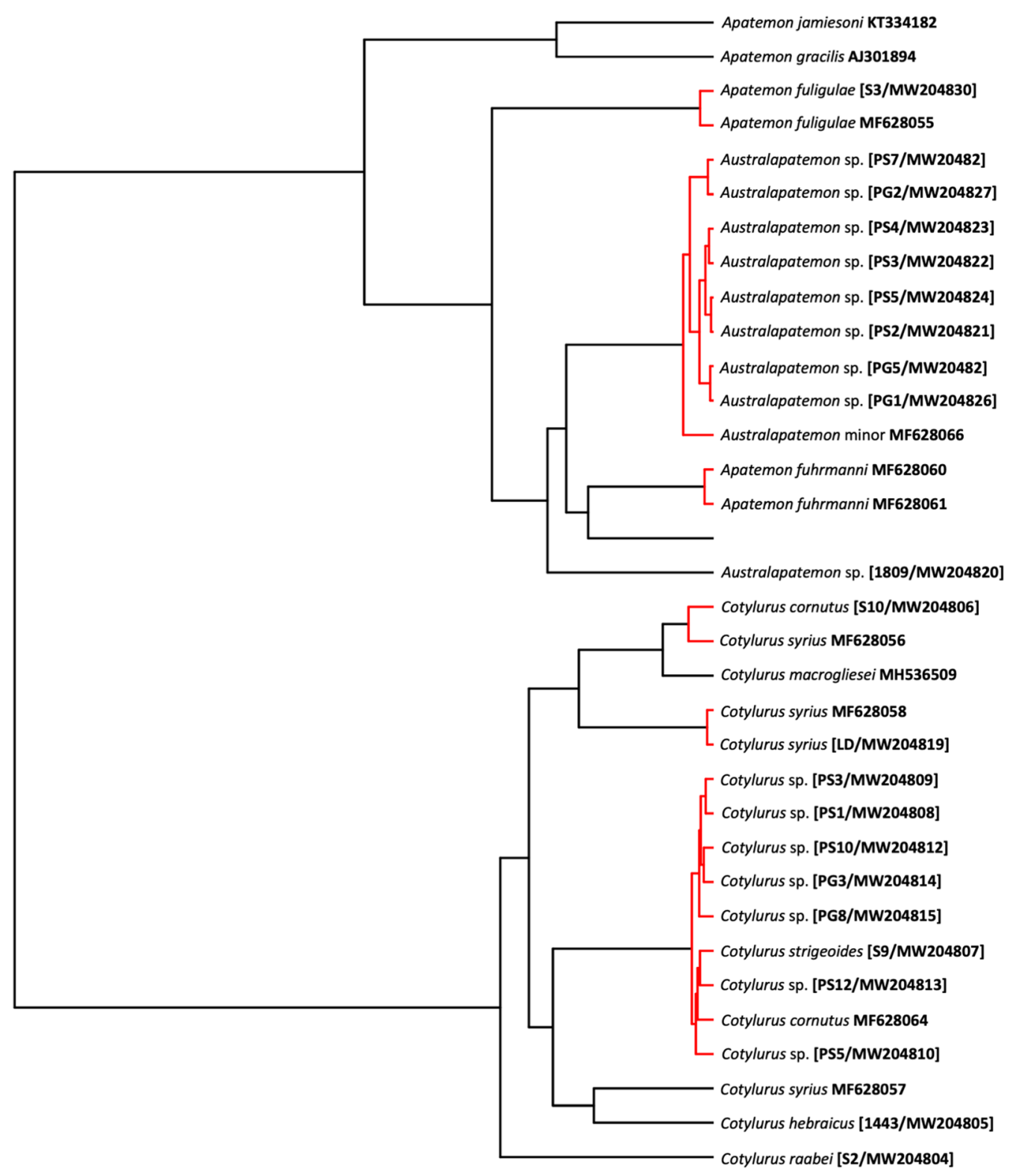

Fig. 5 The Generalised Mixed Yule Coalescent Model (GMYC) analysis. Red lines indicate intraspecific variation, black lines show between species branches

for local bird populations. Taking this information into account, the absence of metacercariae of C. cornutus in the helminth fauna of leeches can suggest that the invasive form of this trematode species does not use leeches as intermediate hosts. This observation, along with other recently obtained results (identification of C. syrius and C. strigeoides in the leech helminth fauna), supports the hypothesis previously formulated by Sudarikov et al. [45] and Vojtek et al. [4] that tetracotyles of C. cornutus occur only in snail intermediate hosts, while the tetracotyle form detected in leeches represents different species of Cotylurus. Moreover, the real species composition and molecular diversity within the genus Cotylurus that utilises various invertebrate hosts (snails and leeches) remains unknown. Additionally, the results presented here clearly indicate the separation of ecological niches and life cycles between some species of Cotylurus, with potential serious evolutionary consequences for a wide range of host-parasite relationships.

The results obtained in the present study clearly confirm the validity of the genus Cotylurus. All markers placed analysed members of this genus in one, 
well-supported clade, with high diversity within the clade. However, the observed phylogenetic relationships within Cotylurus varied in relation to the analysed loci, which, in our opinion, reflects the limited availability of fully reliable comparative sequences from related taxa in GenBank. Despite this, the sequenced specimens of $C$. strigeoides (both adults and tetracotyle) formed a well-supported separate clade that was particularly well defined in the phylogeny based on $28 \mathrm{~S}$ rDNA loci (Fig. 2). In the analysis based on the ITS2 marker, isolates of C. strigeoides created a sister branch to a single isolate of C. gallinulae (JX978441) sampled from Aythya affinis in Mexico and provided by Hernández-Mena et al. [56] (Fig. 3). Heneberg et al. [14] suggested a high level of similarity between some lineages of C. cornutus (isolates from Anas crecca from the Czech Republic) and sequences C. gallinulae (JX978441), but our phylogeny, based on several new isolates and supplemented by GenBank data, did not confirm these assumptions. The current phylogeny based on ITS2 sequences (length $270 \mathrm{bp}$ ) revealed only $0.4 \%$ difference (1 nucleotide) between C. gallinulae (JX978441) from Mexico and recently obtained sequences of $C$. strigeoides (both adults and metacercariae), which strongly suggests that they are conspecific. Moreover, Locke et al. [32] suggested the identity of COI sequences of Cotylurus strigeoides sampled from Aythya collaris in Canada (MH581280-2) and C. gallinulae (JX977781) provided by Hernández-Mena et al. [56]. Importantly, both JX978441 and recently sequenced adult specimens of $C$. strigeoides were sampled from anatid birds, which are recognised as the typical final hosts for this trematode species, while C. gallinulae is recognised as a typical parasite of Rallidae. According to Locke et al. [32], this suggests the possibility of incorrect determination of the material from Mexico. Another interesting question related to the position of C. gallinulae is the validity of recently sequenced specimens of Cotylurus hebraicus. This species was first described on the basis of trematodes collected from the Eurasian coot Fulica atra sampled in Syria and further placed as a subspecies within Cotylurus gallinulae as C. gallinulae hebraicus together with C. gallinulae gallinulae (Lutz, 1928) Dubois, 1937, C. gallinulae ban Yamaguti, 1939 and C. gallinulae vitellosus Lumsden et Zischke, 1963, which suggests their close affinity [19]. All these taxa are recognised as typical parasites of coots, moorhens and rails, but with different geographical distributions. Some authors [57-59] have recognised $C$. hebraicus as a valid taxon with species rank, and this has been confirmed in a recently obtained phylogeny, but the real taxonomic position and validity of other subspecies remain to be established. In our opinion, given their morphological similarity and narrow range of hosts, subspecies within C. gallinulae should be treated as a synonym of C. hebraicus. Confirmation of this hypothesis requires a detailed analysis of strigeid trematodes collected from typical avian final hosts (Rallidae) from a wide geographic distribution and comparison with sequenced specimens of $C$. hebraicus and other Cotylurus taxa.

Our results reveal the unclear taxonomic position and composite structure of $C$. syrius and C. cornutus, as reported previously by Heneberg et al. [14]. According to these authors, trematode specimens morphologically identified as C. syrius and sampled from the typical host, the mute swan Cygnus olor, represent two distinct molecular lineages: one recognised as the typical $C$. syrius (s.s.), and the other, according to Heneberg et al. [14], as a C. cornutus-like isolate due to its similarity to sequences obtained from adult specimens of C. cornutus sampled from Eurasian teal Anas crecca. Recently obtained sequences of the COI and ITS2 loci obtained from metacercariae sampled from Haemopis sanguisuga from Gdańsk Pomerania and adult trematodes collected from a swan from Kraków are almost identical to sequences obtained by Heneberg et al. [14] from adult specimens of C. syrius (s.s.) (MF628093, MF628099 for ITS2; MF628057, MF628059 for COI) (Figs. 3, 4). The identity of the above-mentioned sequences was also confirmed using the $28 \mathrm{~S}$ rDNA locus (Fig. 2). Additionally, sequences of the ITS2 fragment isolated from adult specimens of C. syrius sampled from Cy. olor from Lower Silesia were found to be closely related to the sequence reported by Heneberg et al. [14] (MF628091) and are described as C. cornutus-like isolates of C. syrius (Fig. 3). Phylogenetic reconstruction based on the COI locus and the GMYC analysis revealed a separate lineage clustering C. cornutus-like C. syrius with isolates of $C$. cornutus obtained from the typical definitive host, the mallard Anas platyrhynchos (Fig. 5). Sequences of the COI locus of $C$. cornutus obtained in the current study differed from sequences reported by Heneberg et al. [14] under the name C. cornutus (MF628064) and were almost identical to recently sequenced adult specimens and the tetracotyle of C. strigeoides (Fig. 4, 5). The obtained sequences supplemented with GenBank data clearly confirmed the existence of three distinct lineages within species morphologically identified as $C$. syrius: one lineage identified by Heneberg et al. [14] as C. syrius (s.s.), recorded from the definitive host $C y$. olor from the Czech Republic and Poland (Kraków) and in the tetracotyle from the leech $H$. sanguisuga from Gdańsk Pomerania, and two lineages identified by Heneberg et al. [14] as C. cornutus-like $C$. syrius. One of these grouped some specimens of $C$. syrius sampled from a typical definitive host, the swan Cy. olor, from the Czech Republic and Poland (Lower Silesia), and the second, collected from Cy. olor from the Czech 
Republic. The COI locus of the latter is almost identical to that of $C$. cornutus collected from the typical definitive host, the mallard A. platyrhynchos from Poland (Vistula Lagoon). In this context, swans in central Europe can be parasitised by three (not 2 , as suggested previously by Heneberg et al. [14]), morphologically indistinguishable but molecularly different species of Cotylurus, classified as $C$. cornutus or $C$. syrius, which strongly suggests that these lineages represent a complex of cryptic species. In this regard, our results clearly reveal the urgent need to verify the validity and range of morphological criteria enabling the identification of adult specimens of some Cotylurus species. Moreover, based on the obtained results, we cannot exclude that the observed situation is a consequence of separation of ecological niches and hosts of tetracotyle between C. syrius (s.s.) lineages (tetracotyle in leeches) and a Cotylurus-like C. syrius lineage (tetracotyle in snails).

Recently obtained data have revealed the separate position of Cotylurus raabei within Cotylurus. For many years, this species was placed in the genus Cotylurus [19], Cotylurostrigea Sudarikov, 1961 [27, 57] or Strigea $[20,26]$. Based on the results of morphological and cladistics analyses, Zazornova and Sysoev [28] synonymised Cotylurostrigea with Cotylurus and placed C. raabei within the latter. In the phylogeny based on $28 \mathrm{~S}$ rDNA and COI markers, the position of this species is separate, forming a sister branch to the other Cotylurus species (Figs. 2, 4), and C. raabei is clearly distinct, while in the phylogeny based on the ITS region this species is placed in a lineage between the recently sequenced $C$. hebraicus and isolates of cercarial Cotylurus sp. infecting Biomphalaria straminea in Brazil (MN179272 and MN179271) [16]. The ITS2 sequences (270 bp) from $C$. raabei differed by $4.8 \%$ from those of $C$. hebraicus and by 5.2\% from those of Cotylurus sp. from Brazil (MN179272 and MN179271). Given the inconsistent results obtained from the analysis of different loci, the taxonomic status of C. raabei remains unexplained and awaits further studies.

Another problem that is rarely mentioned in the contemporary literature is the identification, genetic variability and taxonomic position of metacercariae of Australapatemon from leeches. Due to their morphological similarity, the metacercariae and adults of Australapatemon have for many years been erroneously confused with Apatemon (e.g. [6]). According to the literature, one of the features enabling fully reliable differentiation between the genera Australapatemon and Apatemon (other than the structure of excretory systems in cercariae) is the host of the invasive stages (fish in Apatemon, leeches in Australapatemon). However, this is not true in all cases. Negm-Eldin and Davies [60] revealed that metacercariae of Apatemon hypseleotris from Australia can develop in both leeches and fish. Considering that the structure of cercariae of A. hypseleotris is typical for genus Australapatemon (14 flame cells), the taxonomic position of this species should be elucidated in further analyses [6]. Another species of Apatemon with a doubtful taxonomic position and metacercariae in leeches is Apatemon jamesi [61]. On the other hand, all species of Australapatemon with described life cycles utilise leeches as the hosts of invasive stages $[6,10,20$, 62-65]. Unfortunately, studies on the molecular identification, taxonomic position and diversity of Australapatemon metacercariae occurring in leeches from various ecosystems are scarce $[6,12]$.

Similar to the phylogenetic relationships within the genus Cotylurus discussed above, the phylogenetic relationships among Australapatemon varied with the loci analysed, which again, in our opinion, reflects the limited availability of fully reliable comparative sequences of related taxa in GenBank. Our data illustrate the inconsistent and confusing taxonomic status of sequenced tetracotyles of Australapatemon. Regarding the 28S rDNA fragment, the results revealed the greatest similarity to the sequences of $\mathrm{Au}$. burti from Mexico (MF39834299.9\%, 1-nucleotide difference) and Au. niewiadomski from New Zealand (KT334164, KT334165-99.4\%, 6-nucleotide difference) (Fig. 2). These results are in partial disagreement with sequences of the ITS2 fragment recently sampled from metacercariae from leeches that showed $100 \%$ similarity with sequences described as Au. minor from Anas platyrhynchos from the Czech Republic (MF628095) and Au. burti from cercariae from Slovakia (KU950451) and the USA (KY570947). Moreover, to increase confusion, the sequences of ITS2 were also similar to those from a trematode identified as Au. mclaughlini (1-nucleotide difference compared to recently obtained isolates) and $A u$. burti from Mexico (2-nucleotide difference). The COI sequence analysis also gave inconclusive results: all sequences were placed in a separate clade, sister to Au. minor (MF628066) from Anas platyrhynchos from the Czech Republic (Fig. 4), and revealed high intraspecific diversity. Therefore, in the light of the most recent available molecular data, tetracotyle of Australapatemon represents, most probably, Au. minor. However, due to the lack of comparable molecular data (preferably multi-locus) derived from type localities of $A u$ minor and $A u$. burti, the phylogenetic relationship between both species is still unclear. Therefore, we assume that the second scenario, where $A u$. minor is a junior synonym of $A u$. burti, is also possible. The taxonomic position of the trematode identified as Australapatemon sp. collected from Anas strepera from Vistula Lagoon is also ambiguous: recently obtained sequences of $28 \mathrm{~S}$ rDNA showed $100 \%$ homology with 
previously published sequences of $A u$. burti from Canada (KY207625) [13] and Mexico (MF398342) [66]. Regarding the ITS2 fragment, our isolates presented the highest similarity with sequences of Australapatemon sp. (MK168687 and MK168688) from France [25]. Based on the COI locus, an isolate of Australapatemon sp. from Anas strepera creates a separate branch to all other Australapatemon sequences available in GenBank, indicating its separate position (Fig. 4).

The phylogeny based on 28 rDNA and ITS2 also revealed unclear relationships between $A u$. burti and Au. minor. Australapatemon burti (Miller, 1923) was originally described from North America and often misreported as Apatemon gracilis [17, 63, 67-69], and has recently been widely recorded from the Holarctic (central Europe) [23, 70, 71] and neotropical regions [6, 56, $72,73]$, and references therein], but only few of these records outside North America have been confirmed by molecular analysis $[23,56]$. However, these data strongly suggest the cosmopolitan distribution of this species. Australapatemon minor Yamaguti, 1933 is recognised as a typical parasite of Anseriformes in the Palearctic region $[19,74]$. Therefore, the sympatric occurrence of these two species ( $A u$. burti and Au. minor) in the territory of central Europe would not be surprising. Moreover, as mentioned above, the study area in Gdańsk Pomerania (near the Gulf of Gdańsk and Vistula Lagoon) is recognised as a well-known refuge of water and wetland birds. In addition to the rich and diversified fauna of breeding birds, these places are an important resting place for birds migrating mainly from the north and north-east [75], which creates the possibility of some species of helminths being brought into the area by migrating birds from nesting grounds located, for example, on the Scandinavian Peninsula or Siberia. As such, helminth taxa unusual for this geographical region could appear, especially in avian definitive hosts during migration. Such conditions mean that extreme caution is required in the interpretation of molecular data. Unfortunately, while fragments of $28 \mathrm{~S}$ rDNA clearly revealed the similarity of recently obtained isolates from tetracotyle and adult Austalapatemon sp. with sequences of $A$. burti, sequences of ITS2 isolates from tetracotyle showed $100 \%$ homology with sequences described as Au. minor and Au. burti. The main underlying problem is that the only sequences of ITS2 and COI fragments of $\mathrm{Au}$. minor available in GenBank and provided by Heneberg et al. [14] are rather short (270 bp for ITS2 and $295 \mathrm{bp}$ for COI), which forced the shortening of our sequences and precluded the full comparison of these sequences with other data (based on full-length fragments). In phylogenetic analyses, fragments of this limited length have limited significance and reduce the reliability of any conclusions.
Our results reveal the discursive and inconsistent status of the genera Apatemon and Australapatemon. In the phylogenies based on 28S rDNA and ITS2, all Australapatemon sequences analysed were placed in one, well-supported clade, separate from other strigeid genera (Cotylurus and Apatemon), with the exception of sequences of Apatemon fuligulae, which were located between Australapatemon (Figs. 2, 3). In the phylogeny based on COI fragments, our sequences of Ap. fuligulae were almost identical to sequences of Ap. fuligulae submitted by Heneberg et al. [14] (MF628055), which confirmed the valid determination of this species. Importantly, both isolates were placed in a branch with Australapatemon species. The different generic position of Ap. fuligulae obtained in phylogenies based on various other loci may indicate the inappropriate generic status of this species. These suspicions were confirmed by the phylogeny based on 28S rDNA fragments: sequences of Ap. fuligulae were similar to Canadian sequences of Australapatemon sp. (MF124270, 3-nucleotide difference) provided by Gordy et al. [13] and isolated from an adult trematode specimen collected from the northern pintail Anas acuta and cercariae emerging from Stagnicola elodes. On the other hand, Yamaguti [76] detected the metacercariae of Ap. fuligulae (Tetracotyle fuligulae) in the skin and musculature of fish (Parasilurus asotus, Pseudobagrus aurantiacus) from Lake Biwa. Therefore, the taxonomic position of Ap. fuligulae should be considered as doubtful. Establishing its position will require further studies on both the genetic variability within this species and a detailed analysis of the morphology of cercariae and adults, as well as determination of the second intermediate host (fish or leeches) in the life cycle of $A p$. fuligulae.

To summarise, in our opinion, the unclear and inconsistent status of Apatemon and Australapatemon, which became especially evident using the COI and ITS markers, results mainly from the invalid determination of sequenced adult and larval trematodes: from a morphological point of view, as mentioned in the "Introduction", the two genera are quite similar and often misidentified in the literature. Erroneous determination of sequenced adult and larval stages of both Apatemon and Australapatemon result in the erroneous description of the sequences deposited in GenBank, which increases the chaos in the phylogenies based on them. Based on our own experience concerning the morphology of these genera and their ecology, as well as the literature, both of which show key differences between the life cycles of Apatemon and Austalapatemon, we believe that these genera are valid and distinct, as confirmed by the $28 \mathrm{~S}$ rDNA sequences. However, full confirmation of this assertion requires a meticulous review of all sequences of 
Apatemon and Austalapatemon deposited in GenBank, which is not possible without detailed resolution of the life cycles of particular species within these genera.

\section{Conclusions}

Our study suggests that encysted and non-encysted tetracotyle metacercariae derived from leeches from Poland represent two separate strigeid genera: Australapatemon and Cotylurus. In light of currently available molecular data and the results from the present study, tetracotyle of Australapatemon most probaby represents Au. minor; however, unclear phylogenetic relationships between $A u$. burti and $A u$. minor reduce the reliability of this conclusion. Detected metacercariae of Cotylurus were identified as two species, namely $C$. strigeoides and $C$. syrius. Our ecological and molecular data suggest that tetracotyle of C. cornutus may occur mainly in snail intermediate hosts, while the tetracotyle form detected in leeches represents non- $C$. cornutus species. On this basis, we suggest the separation of ecological niches and life cycles between $C$. cornutus and C. strigeoides/C. syrius with potential evolutionary consequences for a wide range of host-parasite relationships.

\section{Supplementary Information}

The online version contains supplementary material available at https://doi. org/10.1186/s13071-020-04538-9.

Additional file 1: Table S1. Primers used in the present study. Table S2. The list of sequences of digenean representatives available in GenBank used in the molecular analyses. A Adult, $C$ cercaria, $M$ metacercaria

\begin{abstract}
Abbreviations
COI: Cytochrome c oxidase subunit 1; GMYC: Generalised Mixed Yule Coalescent model; GTR + I + G: General time reversible model with estimates of invariant sites and gamma distributed among-site variation; HKY + G: Hasegawa-Kishino-Yano substitution model with gamma distributed amongsite variation; ITS: Internal transcribed spacer region; ITS2: Second internal transcribed spacer region; mtDNA: Mitochondrial DNA; rDNA: Ribosomal DNA; 28S: Nuclear large ribosomal subunit gene.
\end{abstract}

\section{Acknowledgements}

We kindly thank Dr. Marta Basiaga (Faculty of Animal Science, University of Agriculture in Kraków, Poland) for providing trematode material from the mute swan. The authors are very grateful to Wiesław Podsiadły, Hunting Club "Żuławy" in Nowy Dwór Gdański, Poland, for providing specimens of ducks and coots from Vistula Lagoon. We also highly acknowledge Iwona Maściuch and Anna Wojtoń for helping in the parasitology studies in the laboratory.

\section{Authors' contributions}

$\mathrm{JH}$ and EP conceived and designed the study. JH and GK collected leeches in the field. EP performed necropsy of annelids and processed material for further research. GK sampled and identified trematode specimens from avian hosts. EP, JH and GZ performed molecular and phylogenetic analyses. EP, GK and $\mathrm{JH}$ drafted the manuscript. All authors read and approved the final manuscript.

\section{Funding}

Research work was partially financed by the project of the Minister of Science and Higher Education (Poland) under the name: "luventus plus", Grant no. 9003/IP1//2015/73

\section{Availability of data and materials}

All data generated or analysed during this study are included in present article and additional files, all necessary sequences were deposited in GenBank database.

\section{Ethics approval and consent to participate}

Not applicable.

\section{Consent for publication}

Not applicable.

\section{Competing interests}

The authors declare that they have no competing interests.

\section{Author details}

${ }^{1}$ Department of Parasitology, Institute of Genetics and Microbiology, University of Wrocław, Przybyszewskiego 63, 51-148 Wrocław, Poland. ${ }^{2}$ Ornithological Station, Museum and Institute of Zoology, Polish Academy of Sciences, Nadwiślańska 108, 80-680 Gdańsk, Poland. ${ }^{3}$ Department of Systematic and Ecology of Invertebrates, Institute of Environmental Biology, Wrocław University of Environmental and Life Sciences, Kożuchowska 5b, 51-631 Wrocław, Poland.

Received: 27 September 2020 Accepted: 10 December 2020 Published online: 12 January 2021

\section{References}

1. Mann KH. Leeches (Hirudinea). Their structure, physiology, ecology and embryology. London: Pergamon Press; 1962.

2. Wiśniewski WL. Cercaria dubia sp. N. und deren weitere Entwicklung in Herpobdella atomaria. Bull Acad Polon Sci. 1935;Ser.II(1-2):19-36.

3. Dobrowolski K. Parasites of leeches of Drużno Lake. Acta Parasitol Pol. 1958:6:179-94.

4. Vojtek J, Opravilová V, Vojtková L. The importance of leeches in the life cycle of the order Strigeidida. Folia Parasitol. 1967;14:107-20.

5. Sudarikov VE, Shigin AA, Kurochkin YV, Lomakin W, Stenko RP, Yurlova NI. Trematode metacercariae - parasites of freshwater animals in Central Russia. Moscow: Rossiyskaya Akademia Nauk, Izdatelstvo Nauka; 2002 (in Russian).

6. Blasco-Costa I, Poulin R, Presswell B. Species of Apatemon Szidat, 1928 and Australapatemon Sudarikov, 1959 (Trematoda: Strigeidae) from New Zealand: linking and characterising life cycle stages with morphology and molecules. Parasitol Res. 2016;115:271-89.

7. Spelling SM, Young JO. The population dynamics of metacercariae of Apatemon gracilis (Trematoda: Digenea) in three species of lake-dwelling leeches. Parasitology. 1986;93:517-30.

8. Spelling SM, Young JO. Seasonal occurrence of metacercariae of the trematode Cotylurus cornutus (Szidat) in three species of lake-dwelling leeches. J Parasitol. 1986;72:837-45.

9. Spelling SM, Young JO. Predation on lake-dwelling leeches (Annellida: Hirudinea): an evaluation by field experiment. J Anim Ecol. 1987;43:131-46.

10. McCarthy AM. Experimental observations on the specifity of Apatemon (Australapatemon) minor (Yamaguti 1933) (Digenea: Strigeidae) toward leech (Hirudinea) second intermediate host. J Helminthol. 1990;64:161-7.

11. Karvonen A, Faltýnková A, Choo JM, Valtonen ET. Infection, specifity and host manipulation of Australapatemon sp. (Trematoda, Strigeidae) in two sympatric species of leeches (Hirudinea). Parasitology. 2017;144:1-10.

12. Calhoun DM, Esfahani E, Locke SA, Moser WE, Johnson PTJ. How parasite exposure and time interact to determine Australapatemon burti 
(Trematoda: Digenea) infections in second intermediate hosts (Erpobdella microstoma) (Hirudinea: Erpobdellidae). Exp Parasitol. 2020;219:108002.

13. Gordy MA, Locke SA, Rawlings TA, Lapierre AR, Hanington PC. Molecular and morphological evidence for nine species in North American Australapatemon (Sudarikov, 1959): a phylogeny expansion with description of the zygocercous Australapatemon mclaughlini n. sp. Parasitol Res. 2017;116:2181-98.

14. Heneberg P, Sitko J, Těšínský M, Rząd I, Bizos J. Central European Strigeidae Railliet, 1919 (Trematoda: Strigeidida): Molecular and comparative morphological analysis suggests the reclassification of Parastrigea robusta Szidat, 1928 into Strigea Abildgaard, 1790. Parasitol Int. 2018;67:688-701.

15. Gordy MA, Hanington PC. A fine-scale phylogenetic assessment of digenean trematodes in central Alberta reveals we have yet to uncover their total diversity. Ecol Evol. 2019;9:3153-238.

16. López-Hernández D, Locke SA, de Assis JCA, Drago FB, de Melo AL, Rabelo ÉML, et al. Molecular, morphological and experimental-infection studies of cercariae of five species in the superfamily Diplostomoidea (Trematoda: Digenea) infecting Biomphalaria straminea (Mollusca: Planorbidae) in Brazil. Acta Trop. 2019;199:105082.

17. Sudarikov V. Order Strigeidida (La Rue, 1926) Part 1. Morphological characteristics of strigeids and superfamily Strigeoidea Railliet, 1919. In: Skrjabin Kl, editors. Trematodes of animals and man. Osnovy Trematodologii. Moscow: Akad. Nauk SSSR; 1959. p. 217-631 (in Russian).

18. Dubois G, Pearson JC. Quelques Strigeida (Trematoda) IV. Mem Soc Sci Nat Neuchatel. 1965;88:77-99.

19. Dubois G. Synopsis des Strigeidae et des Diplostomatidae (Trematoda). Mem Soc Sci Nat Neuchatel. 1968;10:1-258.

20. Yamaguti S. Synopsis of digenetic trematodes of vertebrates. Tokyo: Keigaku Publishing Co.; 1971

21. Niewiadomska K. Family Strigeidae Railliet, 1919. In: Gibson DI, Jones A, Bray RA, editors. Keys to the Trematoda. Wallingford: CABI Publishing and The Natural History Museum; 2002. p. 231-41.

22. Bell AS, Somerville C. Molecular evidence for the synonymy of two species of Apatemon Szidat, 1928, A. gracilis (Rudolphi, 1819) and A. annuligerum (von Nordmann, 1832) (Digenea: Strigeidae) parasitic as metacercariae in British fishes. J Helminthol. 2002;76:193-8.

23. Aksenova OV, Bespalaya YV, Bolotov IN, Kondakov AV, Sokolova SE. First molecular identification of Australapatemon burti (Miller, 1932) (Trematoda: Digenea: Strigeidae) from an intermediate host Radix labiate (Rossmaessler) (Gastropoda: Lymneidae) in Europe. Zootaxa. 2016;4132:588-90.

24. Nezhybová V, Blažek R, Kašný M, Slamková D, Leontovyč R, Ondračková M. Morphological and molecular characterization of Apatemon sp. infecting killifish in Mozambique. Parasitol Int. 2019;73:101967.

25. Huguenin A, Depaquit J, Villena I, Ferté H. MALDI-TOF mass spectrometry: a new tool for rapid identification of cercariae (Trematoda, Digenea). Parasite. 2019;26:11.

26. Bezubik B. Strigea raabei sp. n., a new trematode from wild ducks of Poland. Acta Parasitol Pol. 1958;6:309-18.

27. Sudarikov VE. A new trematode genus-Cotylurostrigea nov. gen. (family Strigeidae) from water birds. Trudy GELAN. 1961;11:263-4 (in Russian).

28. Zazornova OP, Sysoev AV. Phylogenetic relations between species of the genus Cotylurus and its position in the system of the trematode family Strigeidae. Parazitologiya. 1993:27:69-76 (in Russian).

29. Odening K. Zur Gliederung von Apatemon and Cotylurus (Trematoda, Strigeidae) in Untergattungen. Ber Akad Wiss Berlin. 1969;1 1:285-92.

30. Niewiadomska K. On the necessity of dividing the genus Cotylurus Szidat, 1928 into two valid genera Cotylurus Szidat, 1928 and Ichthyocotylurus Odening, 1969 (Strigeidae). Acta Parasitol Pol. 1971;19:113-20.

31. Beverly-Burton M. Studies on the trematode of British freshwater birds. Proc Zool Soc Lond. 1961;137:13-39.

32. Locke SA, van Dam A, Caffara M, Pinto HA, López-Hernández D, Blanar CA. Validity of the Diplostomoidea and Diplostomida (Digenea, Platyhelminthes) upheld in phylogenomic analysis. Int J Parasitol. 2018:48:1043-59.

33. Bielecki A, Cichocka MJ, Jeleń I, Świątek P, Adamiak-Brud Ż. A checklist of leech species from Poland. Wiad Parazytol. 2011;57:11-20.

34. Ellerby DJ. The physiology and mechanics of undulatory swimming: a student laboratory exercise using medicinal leeches. Adv Physiol Educ. 2009:33:213-20.
35. Bush AO, Lafferty KD, Lotz JM, Shostak AW. Parasitology meets ecology its own terms: Margolis et al. revisited. J Parasitol. 1997;83:575-83.

36. Kumar S, Stecher G, Li M, Knyaz C, Tamura K. MEGA X: Molecular Evolutionary Genetics Analysis across computing platforms. Mol Biol Evol. 2018:35:1547-9.

37. Ronquist F, Teslenko M, van der Mark P, Ayres DL, Darling A, Höhna S, et al. MrBayes 3.2: efficient Bayesian phylogenetic inference and model choice across a large model space. Syst Biol. 2012;61:539-42.

38. Darriba D, Taboada GL, Doallo R, Posada D. jModelTest 2: more models, new heuristics and parallel computing. Nat Methods. 2012;9:772.

39. Rambaut A. FigTree v1.4.4. 2009. http://tree.bio.ed.ac.uk/software/figtr ee/. Accessed 17 Nov 2020.

40. Pons J, Barraclough TG, Gomez-Zurita J, Cardoso A, Duran DP, Hazell S, et al.. Sequence-based species delimitation for the DNA taxonomy of undescribed insects. Syst Biol. 2006;55:595-609.

41. Fujisawa T, Barraclough TG. Delimiting species using single-locus data and the generalized mixed Yule coalescent (GMYC) approach: a revised method and evaluation on simulated datasets. Syst Biol. 2013;62:707-24.

42. Bouckaert R, Heled J, Kühnert D, Vaughan T, Wu CH, Xie D, et al. BEAST 2: a software platform for Bayesian evolutionary analysis. PLoS Comput Biol. 2014;10:e1003537.

43. Zhatkanbaeva D. Leeches of Korgalzhyn lakes—second intermediate hosts for Strigeidae trematodes. In: Virbicikas IB, editor. Issues of parasitology of water invertebrates. Vilnius: Institute of Zoology of Latvia SSR; 1980. p. 40-1 (in Russian).

44. Zhatkanbaeva D, Akhmetova B. Leeches of Korgalzhyn lakes and their importance in circulation of strigeids parasites as components of water and ground biocenoses of Kazakhstan. Alma-Ata: Publishing House Nauka; 1981. p. 78-83 (in Russian).

45. Sudarikov VE, Karmanova EM, Bakhmeteva TL. Issues of taxonomical composition of metacercariae of strigeid trematodes from leeches of Volga river. Tr Astrakh Gos Zapovednika. 1962;6:197-202 (in Russian).

46. Rajshite DI. Some data about infection of freshwater leeches of estuaries of Volga and Niemen rivers by metacercariae. Problemy Parazitologii. 1969;1:169-99 (in Russian).

47. Szidat L. Beiträge zur Entwicklungsgeschichte der Holostomiden. III. Über zwei Tetracotylen aus Hirudiniden und ihre Weitereentwicklung in Enten zu Cotylurus cornutus Rud. und Apatemon gracilis Rud. Zool Anz. 1929;86:133-49.

48. Timon-David J. Sur la presence en Camarque et le development experimental de Cotylurus cornutus (Rud.) (Trematode, Strigeidae). Bull Mus Hist Nat Marseille. 1943;3:17-21.

49. Szidat L. Beiträge zur Entwicklungsgeschichte der Holostomiden. Die Cercariae des Entenparasiten Apatemon (Strigea) gracilis Rud. und Ihre Entwicklung im Blutgewässystem des Zwischenwirtes (Herpobdella atomaria Car.). Z Parasitenkd. 1931:3:160-72.

50. Zajiček D. Experimental infection of domestic birds by Cotylurus strigeoides Dubois, 1958 (Trematoda: Strigeidae). Folia Parasitol. $1971 ; 18: 113-8$

51. Zazornova OP. Study on life cycle of Cotylurus hebraicus Dubois, 1934 (Trematoda, Strigeidae). Trudy GELAN. 1987;35:31-7 (in Russian).

52. Zazornova OP. A new trematode species Cotylurus szidati n. sp. (family Strigeidae) with comments on taxonomy of the genus Cotylurus. Trudy GELAN. 1991;38:32-43 (in Russian).

53. Zazornova OP. To morphological identification larval forms of the trematodes of genus Cotylurus. Trudy GELAN. 1993;39:39-44 (in Russian).

54. Rząd I, Dzika E, Zalewski K, Śmietana P, Busse P. Geographic and ecologic aspects of the community structure of trematodes of mallards (Anas platyrhynchos) in northern Poland and the Czech Republic. J Wildl Dis. 2020;56:576-87.

55. Schwelm J, Soldánová M, Vyhlídová T, Sures B, Selbach C. Small but diverse: larval trematode communities in the small freshwater planorbids Gyraulus albus and Segmentina nitida (Gastropoda: Pulmonata) from the Ruhr River, Germany. Parasitol Res. 2018;117:241-55.

56. Hernández-Mena DI, García-Prieto L, García-Varela M. Morphological and molecular differentiation of Parastrigea (Trematoda: Strigeidae) from Mexico, with the description of a new species. Parasitol Int. 2014;63:315-23.

57. Sudarikov VE. Trematodes of the fauna of the USSR. Strigeids. Moscow: Izdatielstvo Nauka; 1984. 
58. Sitko J, Faltỳnkova A, Scholz T. Checklist of the trematodes (Digenea) of birds of the Czech and Slovak Republics. Praha: Academia; 2006.

59. Sitko J, Heneberg P. Systematic collapse of a host-parasite network associated with wetland birds in Europe. Parasitol Res. 2020;119:935-45.

60. Negm-Eldin M, Davies RW. Morphology and life cycle of Apatemon hypseleotris species novum from Australia including metacercariae viability and excystment. Dtsch Tierarztl Wochenschr. 2002;109:306-14.

61. Palmieri JR, Krishnasamy M, Sullivan JT. Strigeoid trematodes of Malaysia with descriptions of a new genus and three new species. J Helminthol. 1979:53:51-63.

62. Lutz A. Notas sobre Dicranocercarias brazileiras. Mem Inst Oswaldo Cruz. 1933;27:349-75.

63. Stunkard HW, Willey CH, Rabinowitz Y. Cercaria burti Miller, 1923, a larval stage of Apatemon gracilis (Rudolphi, 1819) Szidat, 1928. Trans Am Micros Soc. 1941;60:485-97.

64. Dubois G. Les Strigeata (Trematoda) de la collection A. Lutz. Mem Inst Oswaldo Cruz. 1970;68:169-76.

65. Davies D, Ostrowski de Núñez M. The life cycle of Australapatemon magnacetabulum (Digenea: Strigeidae) from nortwestern Argentina. J Parasitol. 2012:98:778-83.

66. Hernández-Mena DI, García-Varela M, Pérez-Ponce de León G. Filling the gaps in the classification of the Digenea Carus, 1863: systematic position of the Proterodiplostomidae Dubois, 1936 within the superfamily Diplostomoidea Poirier, 1886, inferred from nuclear and mitochondrial DNA sequences. Syst Parasitol. 2017;94:833-48.

67. Dubois G, Rausch RL. Seconde contribution a l'etude des Strigeides (Trematoda) nord-americains. Bull Soc Neuchl Sci Nat. 1948;71:29-61.

68. Dubois G, Rausch RL. A contribution to the study of North American Strigeids (Trematoda). Am Midl Nat. 1950;43:1-31.

69. Dubois G. Nouvelle clé de détermination des groupes systématiques et des genres de Strigeida Poche (Trematoda). Rev Suisse Zool. 1951;58:639-91.

70. Faltýnková A, Niewiadomska K, Santos MJ, Valtonen ET. Furcocercous cercariae (Trematoda) from freshwater snails in Central Finland. Acta Parasitol. 2007:52:310-7.

71. Soldánová M, Kuris AM, Scholz T, Lafferty KD. The role of spatial and temporal heterogeneity and competition in structuring trematode communities in the great pond snail, Lymnaea stagnalis (L.). J Parasitol. 2012;98:460-71.
72. Drago FB, Lunaschi LI, Hinojosa-Saez AC, Gonzalez-Acuna D. First record of Australapatemon burti and Paramonostomum pseudalveatum (Digenea) from Anas georgica (Aves, Anseriformes) in Chile. Acta Parasitol. 2007;52:201-5.

73. Hinojosa-Sáez A, Gonzalez-Acuna D, George-Nascimento M. Hosts specificity, prevalence and between-sites variation in metazoan parasites of Anas georgica Gmelin, 1789 (Aves: Anseriformes) in Chile. Rev Chil Hist Nat. 2009;82:337-45.

74. Sitko J, Faltýnková A, ScholzT. Checklist of the Trematodes (Digenea) of birds of the Czech and Slovak Republics. Praha: Academia; 2006.

75. Goc M, Mokwa T. Birds. In: Przewoźniak M, editors. Construction of a waterway connecting the Vistula Lagoon with the Gdańsk Bay. Biuro Projekt. Wdroż. Ekol. PROEKO; 2012. p. 145-155 (in Polish).

76. Yamaguti S. Studies on the helminth fauna of Japan. Part I. Trematodes of birds, reptiles and mammals. Jap J Zool. 1933;5:1-134.

77. Tkach W, Littlewood DT, Olson PD, Kinsella JM, Świderski Z. Molecular phylogenetic analysis of the Microphalloidea Ward, 1901 (Trematoda: Digenea). Syst Parasitol. 2003;56:1-15.

78. Morgan JAT, Blair D. Nuclear rDNA ITS sequence variation in the trematode genus Echinostoma: an aid to establishing relationships within the 37-collar spine group. Parasitology. 1995;111:609-15.

79. Van der Auwera G, Chapelle S, de Wachter R. Structure of the large ribosomal subunit RNA of Phytophtora megasperma, and phylogeny of the oomycetes. FEBS Lett. 1994;338:133-6.

80. Morgan JA, Blair D. Relative merits of nuclear ribosomal internal transcribed spacers and mitochondrial CO1 and ND1 genes for distinguishing among Echinostoma species (Trematoda). Parasitology. 1998;116:289-97.

81. Bowles J, Blair D, McManus DP. Genetic variants within the genus Echinococcus identified by mitochondrial DNA sequencing. Mol Biochem Parasitol. 1992;54(2):165-73.

82. Mira O, Kuris AM, Torchin ME, Hechinger RF, Dunham EJ, Chiba S. Molecular genetic analyses reveal cryptic species of trematodes in the intertidal gastropod, Batillaria cumingi (Crosse). Int J Parasitol. 2005;35:793-801.

\section{Publisher's Note}

Springer Nature remains neutral with regard to jurisdictional claims in published maps and institutional affiliations. 